\title{
Poverty in Sub-Saharan Africa: The Dynamics of Population, Energy Consumption and Misery Index
}

\author{
${ }^{*}$ Stanley Emife Nwani ${ }^{1}$ \\ Emeka Osuji ${ }^{1}$ \\ 'Pinl-Itlintic Lniversity, Ligos, ligeriia

\begin{abstract}
The purpose of this paper was to examine the impacts of population explosion, misery index, access to adequate sanitation and improved water supply, economic development and electricity consumption on poverty SDG for 20 Sub-Saharan African countries. The study employed annual secondary balanced panel data sourced from World Bank development indicators covering 1990 to 2018. The results of the robust least square and panel least square estimates were reinforcing. The study found that poor access to water and high misery index amplified poverty. Also, access to improved sanitation, population growth, economic development and energy consumption per capita linked with significant poverty reduction in the region. Our empirical result further established some level of causation between poverty and its predictors except inflation. The implication of our findings is significant for policy direction and drive towards the attainment of poverty SDG in the region. To achieve this, countries in the area should increase the supply of improved water, create more jobs and formulate anti-inflation policies. Also, better electricity supply, economic development strategies, and the growth of the productive population were suggested for poverty eradication in the region.

Keywords: Access to water, access to sanitation, poverty, misery index, population growth, Sub-Saharan Africa

JEL: I32, J10, N37, 010
\end{abstract}

The menace of poverty is as old as humanity. Its eradication remains a central issue in global political, social, and economic discussions. Poverty causes fierce political and socioeconomic debates, questions of repression, and internal/external instability. It spurs upheavals and violent conflicts (Phillips, 1958). High poverty incidence in the Sub-Sahara African (SSA) region denies millions of people decent livelihood, and entrenches inequality and injustice. It is a clog in the wheel of balanced development and progress, thus, serving as a debilitating obstacle that prevents the actualization of other economic, political, environmental, and social development goals among its other deleterious effects (Anyanwu and Anyanwu, 2017).

Before the era of Sustainable Development Goals (SDGs) (2015-2030), the Millennium Development Goals (MDGs) (2000-2015) notably achieved 50 percent reduction in global poverty incidence from what it was in 1990 (Anyanwu and Anyanwu, 2017). Despite this commendable global result, the proportion of Sub-Sahara Africans affected positively is minuscule and insignificant (Hirst, 
2016). Today, with international poverty line at $\$ 1.90$ per person per day, SSA accommodates the largest number of poor people in the world, having taken over from Asia in 2019 (see the ranking of selected SSA countries in terms poverty positions in Table 1 as proxied by human development performance).

\begin{tabular}{lccccc}
\hline \multicolumn{1}{c}{ Countries } & Ranking & Total & Countries & Ranking & Total \\
\hline Burundi & $185^{\text {th }}$ & 189 & Mozambique & $180^{\text {th }}$ & 189 \\
Cameroon & $150^{\text {th }}$ & 189 & Niger & $189^{\text {th }}$ & 189 \\
$\begin{array}{l}\text { The Central African } \\
\text { Republic } \\
\text { Côte d'Ivoire }\end{array}$ & $188^{\text {th }}$ & 189 & Nigeria & $158^{\text {th }}$ & 189 \\
Ghana & $165^{\text {th }}$ & 189 & Rwanda & $157^{\text {th }}$ & 189 \\
Guinea & $142^{\text {nd }}$ & 189 & Senegal & $166^{\text {th }}$ & 189 \\
Lesotho & $174^{\text {th }}$ & 189 & Togo & $167^{\text {th }}$ & 189 \\
Mauritania & $164^{\text {th }}$ & 189 & Uganda & $159^{\text {th }}$ & 189 \\
Mauritius & $161^{\text {st }}$ & 189 & Zambia & $143^{\text {rd }}$ & 189 \\
\hline Source: Authors' Compilation using World Bank Data (2019) & & $150^{\text {th }}$ & 189 \\
\hline
\end{tabular}

Table 1. Human Development (Poverty Proxy) Ranking of Selected SSA Countries

Poverty eradication in all its forms everywhere is the first bold statement mentioned in the United Nations SDGs. With $1 / 3$ of the total coverage period gone, it has become appropriate to examine progress towards the SDG of poverty alleviation in SSA. Therefore, this study investigates the determinants of poverty in SSA with the purpose to ascertain the effects and causal nexus between poverty and energy consumption, access to improved water, access to quality sanitation, misery index, and population explosion. The outcome of the study would assist economic planners and policymakers in understanding where we are, in terms of poverty eradication programs, what the future poverty eradication strategies should be, the challenges inhibiting progress and the way forward. The attainment of these lofty targets requires a multidimensional understanding in the light of specific social, historical, cultural, economic, and political contexts of the region (Phillips, 1958).

The novelty and contributions of this study to the literature on poverty SDG in SSA are four-fold. Firstly, it employs the most recent and robust data series on poverty using the Human Development 


\section{Nwani \& Osuji}

Index (HDI) as a proxy variable covering the pre-MDGs, MDGs and SDGs era. The use of HDI rather than poverty headcount or poverty gap provides a full explanation of the dynamics of poverty as rationalized by earlier studies (e.g., Antony and Laxmaiah, 2008; Musakwa and Odhiambo, 2019; Workneh, Eshete and Figari, 2019). It therefore improves and extends studies (e.g., Akolgo, 2018; Arndt, McKay and Tarp, 2016; Anyanwu and Anyanwu, 2017; Bicaba, Brixiová and Ncube, 2017; Fosu, 2017) that employed poverty headcount and poverty gap in their analyses. Secondly, the new data series that spanned the three eras (pre-MDGs, MDGs, and SDGs) provided an interesting comparative stylized fact on the progress towards poverty eradication in SSA. Thirdly, the study incorporated energy consumption per capita as rationalized by Destek and Aslan (2017), Esso and Keho (2016), and Okwanya and Abah (2018). Population growth rate justified by earlier studies (e.g., Santos-Vega et al., 2016; Sundaram, 2017), and misery index utilized by earlier studies e.g., Bayar and Aytemiz (2019), and Munir and Asghar (2017). Previous studies on poverty in SSA ignored these variables. Fourthly, the policy implications of the study are relevant for accelerating progress towards alleviating poverty in SSA.

This study was motivated by existing empirical and theoretical lacuna in the literature. First, no existing study on poverty in the SSA region had simultaneously considered the critical roles of energy consumption, access to improved water, access to quality sanitation, misery index, and population explosion as central in poverty alleviation analysis. Again, the study extended the Datt and Ravallion (1992) poverty decomposition theory by incorporating other essential determinants of poverty in addition to population growth. Theoretically, this study argued against the central thesis of poverty decomposition theory that demographic factors accentuates poverty, by proving empirically that population growth does not matter for SSA poverty accentuation, instead, what matters are energy consumption, access to quality water and sanitation, and rising income per head. This finding significantly addresses the theoretical deficiencies of poverty decomposition and salient gaps in the literature on key determinants of poverty in SSA region.

This paper comprises of eight sections. Section 2 details current stylized facts, section 3 is the literature review, section 4 discusses data and methodology, section 5 contains empirical analysis and discussion of the result, section 6 is the conclusion, section 7 presents the implications of the findings, and section 8 discusses the limitations and future research directions.

\section{Comparative Stylized Facts of SSA and Other Emerging Regions}

Poverty profile and $\mathrm{HDI}$ are inversely related, rising $\mathrm{HDI}$ implies falling poverty incidence. Figure 1 shows that the SSA region is the least rated in terms of $\mathrm{HDI}$, which means the highest poverty incidence. Further evidence reveals that the SSA region grew by about 3 percent between 2017 and 
2018, which is equally the most marginal across areas.

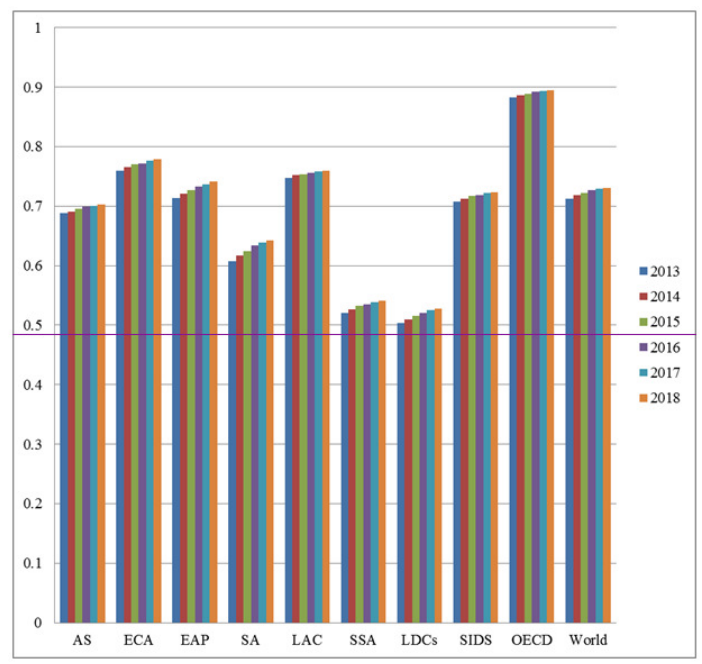

Source: Authors' Computation using World Bank Data (2019)

Figure 1. HDI Ranking Across Regions

Poverty incidence has been discussed as a function of several variables of which energy consumption, access to improved water, access to quality sanitation, misery index, and population explosion are of significant importance. Although education and health are crucial determinants of poverty, the adoption of HDI, which encompasses health and education, justifies the exemption of both variables as predictors of poverty SDG in this study.

In terms of access to sanitation, SSA lags behind other regions with less than 20 percent of its entire population having access to quality and improved sanitation. This is incomparable with East Asia and Pacific (EAP) region with over 62 percent, Europe and Central Asia (ECA) (excluding high income) 65 percent and ECA with 70 percent of its population with access to sanitation. Despite the limited access to sanitation which should naturally imply rising morbidity and declining population, the regions continue to experience population explosion (Figure 2, Appendix-I). The region possesses the highest population growth rate, as depicted in Figure 3 (Appendix-I). In Figure 4 (Appendix-I), the macroeconomic volatility is proxied by the inflation rate. The SSA region has the most volatile macroeconomy; this has tremendous implications for unemployment and economic development captured by gross national income (GNI) per capita (see SSA relative positions in Figures 5-7, Appendix-I). Energy is a crucial determinant of industrialization, which translates to development and poverty reduction (Okwanya and Abah, 2018). Figure 6 (see Appendix-I) shows that SSA also significantly 


\section{Nwani \& Osuji}

lags behind other regions in terms of energy supply and consumption. This has significant implications for poverty reduction and related SDGs.

\section{LITERATURE REVIEW}

\section{Theoretical Underpinnings}

\section{-Poverty Decomposition Theory}

The earlier theoretical works of Datt and Ravallion (1992) on poverty decomposition is adapted to underpin this study. The adaptation of this theory lies in its extension of poverty analysis to population and related demographic factors which other theories had neglected. In their analysis, poverty was determined by growth and redistributive effects (inequality). However, in the later stage of the theory, population dynamics was introduced as a determinant of poverty. It is at that stage that the theory provided an undergirding for this study.

It is often useful to determine whether it is mean-income growth or changes in the relative income shares accruing to different parts of the population that are responsible for the evolution of poverty across time. Investigating this can also help assess whether these two factors, mean-income changes and inequality changes, work in the same or opposite directions when it comes to the behavior of aggregate poverty. Similarly, we may wish to assess whether differences in poverty across countries or regions are due to differences in inequality or to differences in mean levels of income.

There are several ways to do this. To illustrate them, assume that we wish to compare distributions $A$ and $B$ to determine if it is the difference in their mean income ("growth") or the difference in their income inequality ("redistribution") that accounts for their difference in poverty. The common feature of all existing growth-redistribution decomposition procedures is:

-First, to scale the two distributions $A$ and $B$ such that they have the same mean, and interpret the difference in poverty across these two scaled distributions as the impact on poverty of their difference in inequality.

-Second, to interpret the difference in poverty between one of the distributions (say, A) and that same distribution scaled to the mean income of the other distribution (B) as the impact on poverty of their difference in mean income.

Starting from this, the precise growth-redistribution decomposition procedures that are chosen differ by the solution they apply to a fundamental problem known generally in the national-accounts literature as the "index problem". Specifically, at this point, should we scale A to the mean of B, or B to the mean of $A$, to assess the impact of differences in inequality? And, in estimating the impact of differences in mean incomes, should we compare A with A-scaled to the mean of B with B-scaled to 
the mean of $A$ ?

The first paper that implemented a growth-redistribution decomposition of poverty differences (Datt and Ravallion, 1992) used the initial distribution as a reference "anchor point". To see how it is easiest to use the normalized Foster-Greer-Thorbecke (FGT) indices $\overline{\boldsymbol{P}}(\mathrm{z} ; \mathrm{a})$ defined in Equation 1, although the growth-redistribution decomposition methodologies can be used with any relative poverty indices, additive or not. The change in poverty between $A$ and $B$ is expressed as a sum of a "growth" (difference in mean income) effect and a "redistributive" (difference in relative income shares) effect, plus an error term that originates from the index as mentioned above problem. This gives:

$$
\bar{P}_{B}(z ; a)+\bar{P} \mathrm{~A}(\mathrm{z} ; \mathrm{a})=\bar{P}_{B}\left[\frac{Z \mu_{B}}{\mu_{A}} ; \alpha\right]-\bar{P}_{A}\left[\frac{Z \mu_{A}}{\mu_{B}} ; \alpha\right]
$$

This error term is shown to be either the difference between the growth effect measured using $B$ as a reference distribution and that using $A$ as the reference distribution,

$$
\bar{P}_{B}(\mathrm{z} ; \mathrm{a})-\bar{P}_{B}\left[\frac{Z \mu_{B}}{\mu_{A}} ; \alpha\right]=\bar{P}_{A}\left[\frac{Z \mu_{A}}{\mu_{B}} ; \alpha\right]-\bar{P} \mathrm{~A}(\mathrm{z} ; \mathrm{a})
$$

or the difference between the redistribution effects measured using $B$ as the reference distribution and the redistribution effects using $A$ as the reference distribution,

$$
\bar{P}_{B}(\mathrm{z} ; \mathrm{a})-\bar{P}_{A}\left[\frac{Z \mu_{B}}{\mu_{B}} ; \alpha\right]=\bar{P}_{B}\left[\frac{Z \mu_{A}}{\mu_{A}} ; \alpha\right]-\bar{P} \mathrm{~A}(\mathrm{z} ; \mathrm{a})
$$

An alternative decomposition uses the posterior distribution $B$ as the reference distribution for assessing the growth and redistribution effects, and this results in,

$$
\bar{P}_{B}(\mathrm{z} ; \alpha)+\bar{P}_{A}(z ; \alpha)=\bar{P}_{B}(\mathrm{z} ; \alpha)-\bar{P}_{B}\left[\frac{Z \mu_{B}}{\mu_{A}} ; \alpha\right]+\bar{P}_{B}(\mathrm{z} ; \alpha)-\bar{P}_{A}\left[\frac{Z \mu_{A}}{\mu_{B}} ; \alpha\right]
$$

Equation 5 shows poverty expressed as the sum of the poverty contributions of the various subgroups that make up a population. Each sub-group contributes to the population and to the level of poverty found in that sub-group. Hence, we may wish to express changes in poverty across time or space as a function of differences in these factors. More precisely, we want to see whether differences in poverty across distributions can be attributed to differences in demographic or sectoral composition across these distributions or differences in poverty across these demographic or sectoral groups. We 


\section{Nwani \& Osuji}

may express this as follows:

$\bar{P}_{\mathrm{B}}(\mathrm{z} ; \alpha)-\bar{P}_{\mathrm{A}}(\mathrm{z} ; \alpha)=\sum_{k}^{K} \emptyset_{\mathrm{A}}(\mathrm{k}) \bar{P}_{\mathrm{B}}(\mathrm{k}, \mathrm{z} ; \alpha)-\bar{P}_{\mathrm{B}}(\mathrm{k}, \mathrm{z} ; \propto)+\sum_{k}^{K} \quad \bar{P}_{\mathrm{A}}(\mathrm{k}, \mathrm{z} ; \propto)\left(\emptyset_{\mathrm{B}}(\mathrm{k})-\emptyset_{\mathrm{A}}(\mathrm{k})\right)+\sum_{k}^{K} \quad \bar{P}_{\mathrm{B}}(\mathrm{k}, \mathrm{z} ; \propto)$

$-\bar{\Gamma}_{B}(k, z ; \propto)\left(\emptyset_{B}(k)-\emptyset_{A}(k)\right)$

\section{-The Impact of Demographic Changes}

Alternatively, the decomposition shown in Equation 5 also computes the impact of a change in the proportion of the population that is found in a group $k$; this change is accompanied by a precisely offsetting change in the proportion of the other groups. It may be useful, for instance, if one wishes to predict the impact of migration or demographic changes on national poverty, keeping out within-group poverty. Let the population share of a group $t, Q(t)$, increase by a proportion $\Lambda$ to $Q(t)(1+\Lambda)$, with a proportional fall in the other groups' population share from $Q(\mathrm{t})$ to $Q(\mathrm{t})(1-Q(\mathrm{t}) \Lambda(1-Q(\mathrm{t})))$. Note that the new population shares add up to 1 since:

$$
Q(\mathrm{t})(1+\Lambda)+\sum_{\substack{\mathrm{a}(k) \\ k \neq t}} \frac{(1-Q(\mathrm{t}) \Lambda)}{(1-Q(\mathrm{t})} \sum_{k} \underbrace{}_{k}(\mathrm{l})=1
$$

The net impact of this on poverty is then

$$
\Delta P(\bar{z} ; \alpha)=\left[P(t, \bar{z} ; \alpha)-\sum_{k=t} \frac{\emptyset i k)}{1-\sigma(t)} P(k, z, \alpha)\right] \emptyset(t) \Lambda
$$

Equation 7 with relevant adjustments provides the theoretical backing for the model specification of this study.

\section{-Sociological Theories of Poverty}

The sociological theories of poverty address the causes of poverty from five perspectives. The attributes, culture and religious beliefs, social circumstances, access and entitlements, political and economic conditions, and unpredictable shocks (Cerio, 2019) as the fundamental causes of poverty.

The attributes, beliefs and culture theory identify laziness, population growth, neglect of planning for the future, poor sense of history, violence, early marriages, commitment to the robust family system, bigger family size, overdependence on agriculture, seasonal employment and lack of education as the key determinants of poverty (Bayudan-Dacuycuy and Lim, 2013; Cerio, 2019; Lewis, 1961; Reyes et al., 2012; Schelzig, 2005; Tuason, 2002).

Secondly, the theory of access proposed by Ribot and Peluso (2008) asserts the role of politicoeconomic relations in access to essential assets. Accordingly, the essential assets which, when deprived snowball people into poverty include human capital, social capital, information capital, 
International Journal of Management, Economics and Social Sciences

financial capital, and natural capital. In the case of Nigeria, the political class and their associates have access assets, while the masses do not, as such, the high incidence of poverty in the country.

Also, the political and economic situation argument of poverty cause could be rationalized on the structural theory of poverty, which encompasses the dependency theory, neoliberalism, conflict theory, and the world systems theory. The structural theory alluded to the Marxian beliefs that capitalism is the bane of poverty (Cerio, 2019). This situation results in a low wage rate which perpetuates poverty among the proletariats due to false consciousness. In Nigeria, for instance, civil servants, farmlaborers, informal sector employees earn a meagre salary coupled with the unconducive work environment. Further, the dominance of political and economic oligarchy, unsustained economic growth, persistent inflation, and rising unemployment (misery) or the stagflationary tendencies have contributed to the incidence of poverty in the country.

The social circumstances, as the cause of poverty, are embedded in the functionalist, vicious cycle, and deprivation cycle theories. The functionalist theory argues that the function of an individual is the determinant of his/her social class. However, both the vicious cycle and the cycle of deprivation theories of poverty are vehemently opposed to the individualistic postulation of the functionalist. The former theories argue that society is responsible for individual poverty. The theories attributed social situations such as lack of jobs due to discrimination, low quality of schools, social exclusion, and poor environmental conditions as the causes of poverty.

Finally, the poverty trap or unpredicted shocks theory argues that factors like a natural disaster, economic crisis, and health outcomes are hindrances that perpetuate poverty. In Nigeria, for instance, insurgency, drought due to climate change, and herders-farmers crisis have significant effects on the prevalence of poverty. Also, the current COVID-19 pandemic depicts natural calamity and health condition that have the potential to endear more Nigerians to the poverty trap. This is possible as employment continues to shrink, growth recedes, food prices driving inflation rate in the face of dwindling crude oil price for a monolithic economy.

\section{Empirical Review}

Empirical studies abound on poverty; however, not much is directed at tracking the progress towards ending the scourge of poverty in line with the United Nation's SDGs. Earliest studies on poverty concentrated on its causes. For instance, Free and Cantril (1967) presented one of the most initial works on the causes of poverty. They attributed poverty to individualistic traits such as effort, hard work, will-power, lack of education, laziness, and lack of character. The individualist causes of poverty were further corroborated by other reports like Feagin $(1972,1975)$, and Huber and Form (1973) using national public opinion. The characterizing of poverty as an individualist factor rather than 


\section{Nwani \& Osuji}

a social structure portrays lack of dependence on the government by citizens of the developed world, especially in nations where the capitalist doctrine dominates. However, in developing regions such as parts of Asia and Sub-Saharan Africa, public opinion on causes of poverty is skewed towards the failure of the social contract/social structure, this is evident in the literature even in recent times.

Anyanwu and Anyanwu (2017) investigated the causes of poverty in 44 SSA countries using annual time series data between 1980 and 2013. Most of the casual factors were social structure-dependent. Variables such as high-income inequality, institutionalized democracy, dependence on crude oil, HIV prevalence among female youth, and the rising incidence of civil war, were recorded to significantly propagate poverty in the region. However, factors responsible for the marginal poverty reduction recorded overtime included rising government expenditure on final consumption, increased income per head, higher aid and assistance, urban development and access to adequate and improved potable water. In a similar analysis for China, Long and Meng (2017) examined the causes of poverty, and their empirical evidence attributed poverty incidence to factors like ecology, geography, resource endowment, infrastructure, institution, market, government, history, culture, human capital, farmers' rights and social capital. Again, all these identified factors are more social than individualistic.

Although poverty is widely discussed and analyzed as a quantitative phenomenon, some qualitative dimensions must be interesting for readers of this article. In a recent qualitative analysis of the causes of poverty, Ghys (2018) demonstrated that qualitative factors such as the structural production of poverty relation, the position of people in poverty, solidarity, and political conditions, are essential determinants of poverty. Also, other factors identified include the diffusion, scale and continuation of poverty, and government's existing poverty alleviation programs are crucial determinants of poverty at individual and community levels.

Furthermore, poverty incidence has been attributed to the real sector of the economy. In this regard, agricultural productivity is a crucial determinant of poverty reduction in Africa (Ogundipe et al., 2016). Their study investigated the impact of agricultural productivity on poverty incidence reduction in Africa between 1991 and 2015 by employing system generalized method of moments (SGMM) technique to estimate the parameters of the dynamic panel model. The result revealed that agricultural productivity causes poverty reduction through three channels of income empowerment, market expansion, and sustenance enhancement. Also, other factors that enhanced poverty alleviation included per capita agro-value addition, food production index, and GDP per capita. But the two latter factors were more effective in addressing urban poverty than its rural counterpart. However, rural poverty could be curbed by improved credit to the private sector as reported in their result.

The search for the panacea to the menace of poverty continues to attract considerable attention among scholars and policymakers from other perspectives such as financial development. Zahonogo 
(2017) analyzed the poverty effects of financial development in Africa. Using the generalized method of moments (GMM) technique, the study's empirical result supported economic development effects on poverty positively within certain thresholds, and after that, it does not curb the scourge of poverty in Africa. In furtherance, the study identified other factors such as income per head, macroeconomic stability proxied by the inflation rate, institutional quality proxied by governance index, and secondary enrolment rate, which captured human capital development. Zahonogo's findings on the relations between institutional quality and poverty incidence corroborate the position of Singh and Huang (2015).

From a new frontier of knowledge, poverty incidence is predicated on endogenous factors and as such, requires solutions within the context of the economy or region (Asongu and Nwachukwu, 2016; Kamruzzaman, 2016). Kamruzzaman (2016) documented that for poverty incidence to be addressed, weak economies have to perform magic against their track records in an atmosphere of peace, economic reformation, improved data quality, and certainty about the required investment for poverty eradication. Asongu and Nwachukwu (2016) see poverty scourge as a result of capital flight from emerging countries and suggested purely endogenous strategies to address it.

The implications from the recent reviewed works in literature are enormous on existing gaps in this research space. The most glaring gap in the literature is the lack of consideration of energy availability and consumption as a factor that could affect the level of poverty incidence in Africa. Again, empirical shreds of evidence remain mute on the dynamics of population expansion, misery index, and sanitation. Thus, this study contributed to knowledge by bringing to the fore the effects these neglected and overlooked variables have on poverty incidence in SSA, which are apparent realities.

The population transition theory, the Malthusian population, and the demographic-poverty decomposition theory by Datt and Ravallion (1992) provides theoretical backing that population growth determines the rate of poverty. This position has been empirically supported by Fernihough and Gráda (2018), and Hassan, Abu and Adayi (2018). However, empirical evidence (see Anyanwu and Anyanwu, 2017; Thurlow, Dorosh and Davis, 2019) on whether a lead-lag relationship exists between poverty and population growth in SSA is not found in literature. From the preceding, the study proposes following null hypothesis:

$\mathrm{H}_{01}$ : There is no cause-effect relationship between poverty incidence and population growth in Sub-Saharan Africa (SSA).

Access to quality water and sanitation is critical in poverty eradication (Mansuri et al., 2019; Swe et al., 2020). Earlier studies on poverty in SSA did not simultaneously consider the roles of water and 


\section{Nwani \& Osuji}

sanitation on poverty reduction in the region. The absence of these variables in most of the previous studies neglects the theoretical postulation of the vicious cycle and cycle of deprivation that social deprivations such as poor access to improved water and sanitation perpetuates poverty. Based on literature review, following null hypothesis is proposed:

$\mathrm{H}_{02}$ : Lack of access to potable water and improved sanitation (WASH) does not significantly account for poverty pandemic in Sub-Saharan Africa (SSA).

In addition to population growth, water and the access to improved sanitation, poverty is also affected by several macroeconomic variables such as the rate of inflation, unemployment, energy consumption, and economic development indicator (per capita income). In the light of the preceding, rising inflation and unemployment rate would naturally perpetuate poverty incidence from a theoretical perspective. However, studies on how macroeconomic variables impact on poverty in SSA neglected the interplay between inflation and unemployment. Considering the purported trade-off between inflation and unemployment, one would expect the Phillips curve theory to play out in the effect of inflation and unemployment on poverty. Hence, following is the proposed null hypothesis:

$\mathrm{H}_{03}$ : Misery index and poverty incidence have bidirectional empirical linkage.

Besides, energy supply and consumption are critical to Africa's development, studies such as Destek and Aslan (2017), Esso and Keho (2016), and Okwanya and Abah (2018) posit that energy consumption is central for poverty alleviation within their respective country-specific scopes. However, robust empirical evidence from a regional perspective is required.

$\mathrm{H}_{04}$ : Energy consumption does not bear a significant impact on the high poverty incidence in the Sub-Saharan Africa (SSA) region.

Finally, various studies in the literature have reported the leading roles of per capita income in poverty reduction across the globe (e.g., Anyanwu and Anyanwu, 2017; Ogundipe et al., 2016). The documented negative impact of per capita income on poverty does not imply that rising per capita income causes poverty reduction or vice versa. Thus, the following hypothesis is drawn:

$\mathrm{H}_{05}$ : Poor per capita income does not cause poverty in Sub-Saharan Africa (SSA) region.

\section{METHODOLOGY}




\section{Sample and Procedure}

This study investigated the progress towards SDG of poverty eradication in 20 out of the 46 countries in SSA. The sampling procedure for this finite population followed first the Yamane (1967) sampling theory to choose a sample of 20 out of a finite population of 46 . Also, the selection of the countries that made up the final list for our investigation was based on poverty incidence severity; thus, a purposive sampling design was employed. The annual balanced panel data were sourced from the World Bank development indicators between 1990 and 2018 for analysis. The period dovetailed with the pre-MDGs, MDGs and SDGs era. The sampled countries include Burundi, Cameroon, Central African Republic, Ivory Coast, Ghana, Guinea, Lesotho, Mauritania, Mauritius, Mozambique, Namibia, Niger, Nigeria, Rwanda, Senegal, Sierra Leone, Togo, Uganda, Zambia, and Zimbabwe.

\section{Empirical Model}

Adapting the tenets of the demographic- poverty theory (poverty decomposition) posited by Datt and Ravallion (1992) as well as the frameworks and empirical studies conducted by Anyanwu and Anyanwu (2017), Bayar and Aytemiz (2019), Santos-Vega et al. (2016), Destek and Aslan (2017), Esso and Keho (2016), Munir and Asghar (2017), Okwanya and Abah (2018), and Santos-Vega, Sundaram (2017), our stochastic model equation is thus;

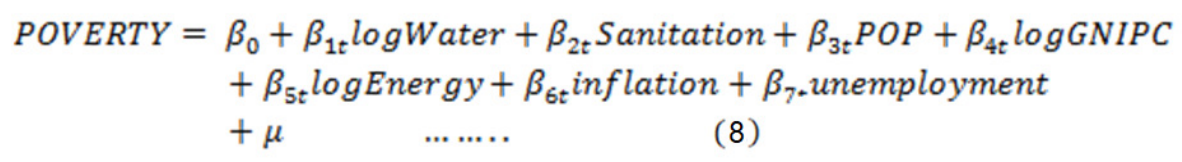

Where poverty is the dependent variable represented by the Human Development Index (HDI), HDI is a composite indicator and a more robust measure of poverty than mere poverty headcount or gap (see Antony and Laxmaiah, 2008; Musakwa and Odhiambo, 2019; Workneh et al., 2019). The Log of Water shows log value of the number of people without access to safe water, sanitation depicts the proportion of the population with access to improved sanitation, POP represents population growth rate (see Santos-Vega et al., 2016; Sundaram, 2017), the log of GNIPC is the log of gross national income per capita, a measure of economic development (see Anyanwu and Anyanwu, 2017), Energy represents electricity consumption per capita (see Okwanya and Abah, 2018), and the combination of the last two variables implies misery index (see Bayar and Aytemiz, 2019; Munir and Asghar, 2017). Furthermore, $\beta_{0} \ldots \beta_{7}$ are the parameters of the model estimated. While $\beta_{0}$ is the natural rate of poverty within the SSA, others are respective elasticity of poverty w.r.t each exogenous variable. The final variable in Equation 8 is the omnibus global variable - the white noise variable. It accounts for possible estimation and measurement errors of poverty. 


\section{Nwani \& Osuji}

\section{Estimation Technique}

The preliminary analysis of data entails descriptive and summary statistics. The empirical model was estimated using panel and robust least square estimation techniques. The choice of these techniques was based on their ability to determine a common effect that is unbiased, efficient, consistent, and sufficient for policy suggestions. The common effect estimated using the panel and robust least squares methods were rationalized by the structural homogeneity of the selected SSA countries utilized for the study. The preceding homogeneity precludes the adoption of the random effect models and the Hausman test which considers the heterogeneous samples. Finally, the Granger causality test conducted to uncover the possibility of causality in either or both directions between poverty and the explanatory variables.

\section{Empirical Analysis}

The result of the summary statistics (Table 2) reveals a weak average HDI of 0.437 , which implies the existence of a high level of poverty in the region. Access to sanitation as a proportion of the population stands at 26.66 percent, implies that over 73 percent of the people in SSA lack access to improved sanitation. Poor sanitation promotes morbidity and increases the death rate, which is expected to

\begin{tabular}{|c|c|c|c|c|c|c|c|c|}
\hline & $\begin{array}{l}\text { HDI_POVERTY } \\
\end{array}$ & INFLATION & $\begin{array}{l}\text { LOGENERGY } \\
\end{array}$ & $\overline{\text { LOGGNI_PC }}$ & POP & SANITATION & UNEMPLO & WATER \\
\hline Mean & 0.437696 & 10.08129 & 2.471971 & 3.235179 & 2.316838 & 26.66087 & 7.169319 & 6.372668 \\
\hline Median & 0.435000 & 6.404386 & 2.686384 & 3.229168 & 2.567156 & 22.48048 & 4.650500 & 6.471801 \\
\hline Maximum & 0.796000 & 183.3120 & 3.400172 & 4.416308 & 8.117928 & 64.92223 & 37.94000 & 7.770658 \\
\hline Minimum & 0.189000 & -9.616154 & 1.086531 & 2.003091 & -6.766223 & 3.162624 & 0.257000 & 3.059721 \\
\hline Std. Dev. & 0.110155 & 15.30433 & 0.439329 & 0.357988 & 1.190110 & 13.57953 & 7.359451 & 0.782948 \\
\hline Skewness & 0.438292 & 5.748458 & -0.484941 & 0.531044 & -1.897665 & 0.850157 & 2.221956 & -1.879069 \\
\hline Kurtosis & 3.675210 & 53.48182 & 2.859913 & 3.504410 & 16.27996 & 2.998209 & 8.033739 & 8.342149 \\
\hline Jarque-Bera & 29.58745 & 64781.00 & 23.20714 & 33.40951 & 4610.080 & 69.86763 & 1089.600 & 1031.002 \\
\hline Probability & 0.000000 & 0.000000 & 0.000009 & 0.000000 & 0.000000 & 0.000000 & 0.000000 & 0.000000 \\
\hline Sum & 253.8636 & 5847.147 & 1433.743 & 1876.404 & 1343.766 & 15463.31 & 4158.205 & 3696.147 \\
\hline Sum Sq. Dev. & 7.025711 & 135614.8 & 111.7527 & 74.20207 & 820.0739 & 106769.7 & 31359.52 & 354.9311 \\
\hline Observations & 580 & 580 & 580 & 580 & 580 & 580 & 580 & 580 \\
\hline
\end{tabular}

Table 2. Descriptive Statistics of Poverty and its Predictors

reduce the population growth rate in the region. Ironically, the average population growth rate is 2.316 percent which is the highest in the world. Also, average calculated misery index (a composite of inflation and unemployment) is 17.27 percent with low energy consumption per capita, gross national 
income per capita, and high rate of the population without access to quality water. Also, statistics revealed further that of all the variables, sanitation and the log energy exhibited properties of mesokurtic distribution, while all other variables reflected leptokurtic distributed (Table 3, Appendix-II). The coefficient of skewness showed that the frequency densities of HDI (poverty proxy), sanitation, $\log G N I$ PC , and misery index taper off slowly from the peak of the distribution towards the right than to the left (positive skewness), while other variables were negatively skewed (Table 4, Appendix-III).

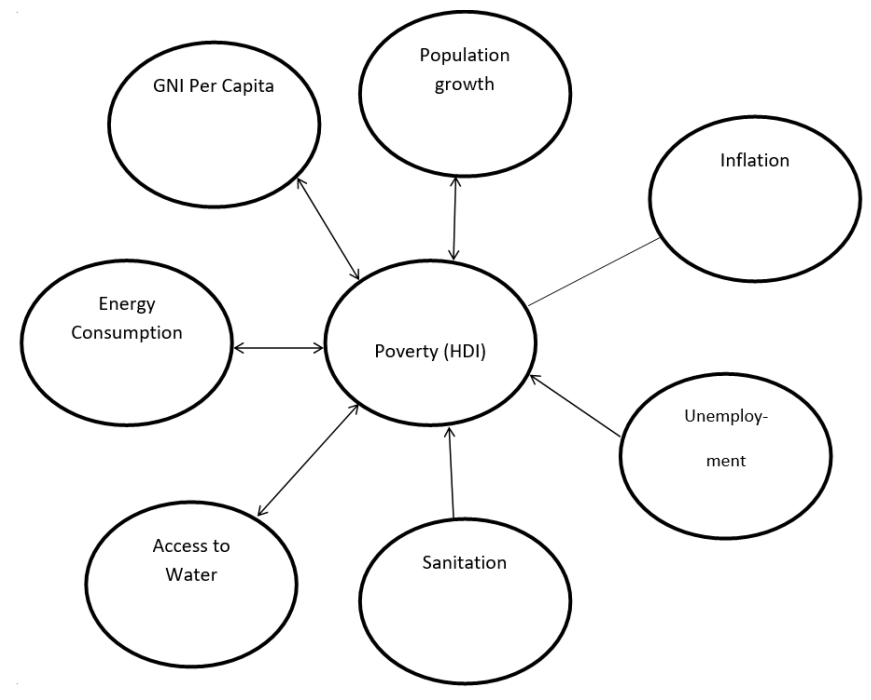

Source: Authors' Presentation

\section{Figure 8. Direction of Causality between Poverty and its Predictors in SSA Economies}

\section{DISCUSSION}

Table 3 shows the results of the estimation of the model using panel least square (PLS) and the robust least square (RLS). The estimated coefficients conform to the a priori expectation of the model. The results of the estimation from both methods are in accord; thus, the estimated model is robust for policy suggestions. Based on the RLS result, cynical and highly significant log water coefficient for HDI (poverty) implies that lower access to improved water is associated with higher poverty in the region. Emphatically, a one percent rise in the population of people without access to water is associated with 0.013 percentage fall in HDI (increase in poverty). Thus, the lack of access to water spells more doom for the poor in the region. This finding is in accord with Dos Santos and Gupta (2017).

Access to improved sanitation is good for HDI (reduces poverty) in SSA economies. The proportion of the population with access to improved sanitation has a positive and significant impact on HDI; thus, poverty reduction. This shows that improving the number of people with access to sanitation in 


\section{Nwani \& Osuji}

SSA countries is crucial for attaining poverty SDG. Our finding conforms with Dos Santos and Gupta (2017), and Kang et al. (2016).

Population growth could either contribute positively to attaining poverty SDG if productive or causes a lack of progress towards it, if unproductive. Our empirical evidence indicates that population growth has a significant positive effect on $\mathrm{HDI}$ and by extension, reduces poverty in SSA countries. An earlier study by Sibt-e-Ali, Raza and Abidin (2018) rationalized this position.

Economic development, proxied by LogGNI_PC, is good for poverty reduction in SSA countries. It has high positive and significant coefficients on HDI. This implies that SSA countries should strategize for the attainment of poverty SDG through economic development. This finding corroborates the results of Anyanwu and Anyanwu (2017), and Ulriksen (2012).

Furthermore, one of the novelty variables of this study - energy consumption (LogEnergy) bears a positive and highly significant impact on HDI (implies poverty reduction) in the region. The size of the coefficient shows that a percentage rise in per capita electricity consumption is associated with 0.0267 percentage increase in $\mathrm{HDI}$ (decline in poverty) in the region. This position is in agreement with the previous studies e.g., Destek and Aslan (2017), Esso and Keho (2016), and Okwanya and Abah (2018).

Finally, high misery index harms HDI (positive association with poverty). This means that rising inflation and unemployment rates are threatening for poverty SDG in the region. Although both variables have a positive association with poverty, the impact of unemployment is more significant than that of inflation. This implies the need for SSA economies to pay more attention to job creation in their bids to attaining poverty SDG in 2030.

In line with our objective to extend and improve on existing studies in this research space, Table 4 and Figure 8 (above) depict the dynamic and causal linkages between poverty and its predictors. The Granger causality test results indicate unidirectional causation running from poverty to the proportion of people without access to improved water. It implies that poverty that limits accessibility to water and not otherwise as widely reported in the literature. Similarly, a unidirectional relationship runs from access to sanitation to poverty reduction. Population growth and poverty exhibit bidirectional

causation. Economic development and poverty also show bidirectionality in causality. Causation runs from poverty to energy consumption but runs from unemployment to poverty without a reversal in both cases.

\section{CONCLUSION}

This paper examined progress towards the attainment of poverty SDG in 20 SSA economies selected 
International Journal of Management, Economics and Social Sciences

using the Yamane (1967) sampling technique and a convenient sampling based on national data available from 1990 to 2018. The poverty decomposition theory and the sociological theories of poverty were employed to undergird the study. The theories provided effective links between Poverty and energy consumption, access to improved water, access to quality sanitation, misery index and population explosion, which were rationalized in the literature. The study adopted the panel least square and robust least squares estimation techniques. Estimates of our empirical model laid the foundation for submitting that access to improved sanitation, rising economic development, higher energy consumption, and increasing population growth rate tend to track poverty, but increase in the population without access to water and increasing misery index (inflation and unemployment) tend to fuel and accentuate poverty in Sub-Saharan Africa. Thus, population growth, energy consumption per capita, economic development and improved sanitation are good for poverty reduction and the actualization of poverty SDG in the region. However, an increase in population without access to water and rising misery index are bad for poverty alleviation and could limit the chances of achieving poverty SDG in the SSA. These conclusions are relevant for poverty alleviation programs in Africa and the other continents of the world with some structural and economic features like Africa.

\section{IMPLICATIONS}

The findings of this study are relevant for critical policy implications on poverty reduction, hence for actualizing poverty SDG in the SSA region. These suggestions could also be adapted by other regions with similar structural characteristics as the SSA region. First, given that the population without access to water accelerates poverty among SSA countries, policymakers at the regional, national and international levels in the area have to tackle the problem of acute quality water supply decisively. This could be done by public provision of improved water in all communities, and corporate bodies should also take on the issue of water provision to their immediate environment as a part of their social responsibilities. At the same time, NGOs should allocate more resources in support of organizations that promote access to quality water supply in SSA. Evidence has shown that a well-coordinated tariff system through private water supply would guarantee efficiency, quality and availability of water supply (see Molinos-Senante and Sala-Garrido, 2017; Rogers, De Silva and Bhatia, 2002; Singh et al., 1993).

Second, the culture of environmental sanitation should be emphasized amongst SSA countries. This positively impacts health, productivity and the SDG of poverty reduction. This linkage is emphasized in literature (see Andersson, Dickin and Rosemarin, 2016; Azqueta and Montoya, 2017). Third, SSA countries should adopt strategies to attain economic development by increasing per capita income. 


\section{Nwani \& Osuji}

Evidence suggests that countries within the SSA region should deepen macroeconomic and structural reforms to enhance competitiveness, create quality jobs, remove structural reform bottlenecks to private and public investments, scale-up investments in infrastructure, and increase productivity through training and re-training (see Anyanwu and Anyanwu, 2017; Biswas, Tortajada and Boey, 2016). Fourth, following our report that population growth alleviates poverty, it means that a productive population has positive effects on poverty reduction. This is a plausible but tricky outcome. While it conforms with our a priori understanding that a large population is not necessarily bad, it must be taken in tandem with the peculiarities of each country. Therefore, each country should pursue an optimum population policy that suits its needs and takes account of its natural endowments. What is critical is the quality of the population, which could be improved for productivity gains through the quality healthcare system and education.

Fifth, there are strong indications that improved electricity supply and consumption per capita would reduce poverty significantly within the region. Africa as a whole has been identified as the "Dark Continent", perhaps for reasons other than electricity (Oppong, 2017; Simmet, 2018). However, the need to lighten up the continent and specifically its SSA region is urgent for attaining poverty SDG. Higher energy supply and consumption enhance small and medium-scale enterprises, which are the bedrock of economic development, employment generation, and poverty reduction (see Nkoro et al., 2019; Nyanzu and Adarkwah, 2016). Sixth and final, the twin evil of unemployment and inflation (misery index) which exacerbates poverty in the SSA region must be tracked head-on. In recognition of the trade-off between unemployment and inflation (see Abu, 2019; Bhattarai, 2016; Phillips, 1958), our empirical findings support a higher focus on tracking unemployment over macroeconomic stability. The finding is justified by the significant adverse effect and causation between unemployment and poverty in the SSA region against the negative but insignificant impact of inflation.

\section{LIMITATIONS AND FUTURE DIRECTIONS}

In light of the above recommendations and conclusion, future research works should focus on other causes of poverty such as environmental, political and cultural dimensions factors. This is because poverty incidence cannot be exhaustively discussed in the SSA region without looking at the culture, politics and environment in which poverty intends to be eradicated. To adequately address these issues, a mixed-method is suggested to effectively capture most qualitative variables which could significantly cause or affect the rate of poverty in the region. The neglect of these qualitative determinants of poverty constitutes the main limitation of this study. Future research studies could address this limitation. 


\section{REFERENCES}

Abu, N. (2019). Inflation and unemployment trade-off: A re-examination of the Phillips curve and its stability in Nigeria. Contemporary Economics, 13(1): 21-35.

Akolgo, I. A. (2018). Agenda 2030 in sub-Saharan Africa: what the millennium development goals' narrative teaches about poverty eradication. African Review of Economics and Finance, 10(1): 3-22.

Andersson, K., Dickin, S., \& Rosemarin, A. (2016). Towards "sustainable" sanitation: Challenges and opportunities in urban areas. Sustainability, 8(12): 1-14. https://doi.org/10.3390/su8121289

Antony, G. M. \& Laxmaiah, A. (2008). Human development, poverty, health \& nutrition situation in India. Indian Journal of Medical Research, 128(2): 198-205.

Anyanwu, J.C. \& Anyanwu, J.C. (2017). The key drivers of poverty in Sub-Saharan Africa and what can be done about it to achieve the poverty sustainable development goal. Asian Journal of Economic Modelling, 5(3): 297-317.

Arndt, C., McKay, A. \& Tarp, F. (2016). Growth and poverty in sub-Saharan Africa. Oxford University Press.

Asongu, S. \& Nwachukwu, J. (2016). Rational asymmetric development, piketty and poverty in Africa. The European Journal of Comparative Economics, 13(2): 221-246.

Azqueta, D., \& Montoya, Á. (2017). The social benefits of water and sanitation projects in Northern Colombia: Cost-benefit analysis, the water poverty index and beyond. Development Policy Review, 35, 118-139. https://doi.org/10.1111/dpr.12285

Bayar, Y. \& Aytemiz, L. (2019). The misery index, corruption and income inequality in Latin American Countries: A panel cointegration and causality analysis. Scientific Annals of Economics and Business, 66(3): 309-319.

Bayudan-Dacuycuy, C., \& Lim, J. A. (2013). Family size, household shocks and chronic and transient poverty in the Philippines. Journal of Asian Economics, 29, 101-112. http://dx.doi.org/10.1016/j.asieco.2013.10.001

Bhattarai, K. (2016). Unemployment- inflation trade-offs in OECD countries. Economic Modelling, 58, 93-103. https://doi.org/10.1016/j.econmod.2016.05.007

Bicaba, Z., Brixiová, Z. \& Ncube, M. (2017). Can extreme poverty in sub-Saharan Africa be eliminated by 2030? Journal of African Development, 19(2): 93-110.

Biswas, A. K., Tortajada, C. \& Boey, A. (2016). Corruption, economic development and poverty alleviation. The Diplomat, 1-4.

Santos-Vega, M., Bouma, M. J., Kohli, V. \& Pascual, M. (2016). Population density, climate variables and poverty synergistically structure spatial risk in urban malaria in India. PLoS Neglected Tropical Diseases, 10(12): 51-55.

Cerio, C. T. (2019). Revisiting the sociological theories of poverty: Conceptualising a framework for rural poverty in the Philippines. Transatlantic Journal of Rural Research, 1(1): 33-52.

Datt, G. \& Ravallion, M. (1992). Growth and redistribution components of changes in poverty measures: A decomposition with applications to Brazil and India in the 1980s. Journal of Development Economics, 38(2): $275-295$. https://doi.org/10.1016/0304-3878(92)90001-P

Destek, M. A. \& Aslan, A. (2017). Renewable and non-renewable energy consumption and economic growth in emerging economies: Evidence from bootstrap panel causality. Renewable Energy, 111, 757-763. https://doi.org/10.1016/j.eneco.2012.08.021

Dos Santos, R. \& Gupta, J. (2017). Pro-poor water and sanitation: operationalising inclusive discourses to benefit the poor. Current Opinion in Environmental Sustainability, 24, 30-35. https://doi.org/10.1016/j.cosust.2017.01.004

Esso, L. J. \& Keho, Y. (2016). Energy consumption, economic growth and carbon emissions: Cointegration and causality evidence from selected African countries. Energy, 114, 492-497. https://doi.org/10.1016/j.energy.2016.08.010

Feagin, J.R. (1972). "When it comes to poverty, it is still 'God helps those who help themselves'." Psychology Today, 6, 101129.

Feagin, J. R. (1975). Subordinating the Poor. Englewood Cliffs, NJ: Prentice-Hall.

Fernihough, A. \& Gráda, C. (2018). Poverty and population in pre-famine Ireland. Queen's University Centre for Economic History Working Paper, 1-5, http://dx.doi.org/10.2139/ssrn.3296291

Fosu, A. K. (2017). Growth, inequality, and poverty reduction in developing countries: Recent global evidence. Research in Economics, 71(2): 306-336. https://doi.org/10.1016/j.rie.2016.05.005

Free, L. \& Cantril, H. (1967). The political beliefs of Americans: A study of public opinion. New Brunswick, NJ: Rutgers University Press.

Ghys, T. (2018). Analysing social innovation through the lens of poverty reduction: five key factors. European Public and Social Innovation Review, 2(2): 1-14. https://doi.org/10.31637/epsir.17-2.1

Hassan, O. M., Abu, J. \& Adayi, J. O. (2018). An analysis of the population-poverty cycle in Nigeria: Implications for human welfare. Journal of Emerging Trends in Economics and Management Sciences, 9(3): 151-159.

Hirst, J. A. (2016). Reaching the millennium development goals: sub-Saharan Africa and the reduction of extreme poverty. https://digitalshowcase.lynchburg.edu/studentshowcase/2016/Presentations/16/

Huber, J., \& Form, W. H. (1973). Income and ideology: An analysis of the American political formula. New York: Free Press.

Kamruzzaman, P. (2016). A critical note on poverty eradication target of sustainable development goals. European Journal of Sustainable Development, 5(2): 87-110. https://doi.org/10.14207/ejsd.2016.v5n2p87

Kang, E., Delzell, D. A., McNamara, P. E., Cuffey, J., Cherian, A. \& Matthew, S. (2016). Poverty indicators and mental health functioning among adults living with HIV in Delhi, India. AIDS Care, 28(4): 416-422. https://doi.org/10.1080/09540121.2015.1099604

Lewis, O. (1961). The children of Sanchez: Autobiography of a Mexican family. New York: Random House.

Long, Y. A. N. G. \& Meng, L. I. (2017). Research on the causes and mechanism of poverty with comments on the policy of poverty alleviation in China. Journal of South China Normal University, 4, 1-5.

Mansuri, G., Sami, M. F. Ali, M. Doan, H. T. T. Javed, B. \& Pandey, P. (2018). When water becomes a hazard: A diagnostic 


\section{Nwani \& Osuji}

report on the state of water supply, sanitation and poverty in Pakistan and its impact on child stunting (No. 131860, pp. 1151). The World Bank.

Molinos-Senante, M., \& Sala-Garrido, R. (2017). How much should customers be compensated for interruptions in the drinking water supply? Science of The Total Environment, 586, 642-649. https://doi.org/10.1016/j.scitotenv.2017.02.036

Munir, S., \& Asghar, N. (2017). An Analysis of the interrelationship among crime, misery index and institutional quality: A case study of Pakistan. Journal of Political Studies, 24(1): 383-406.

Musakwa, M. T. \& Odhiambo, N. M. (2019). FDI and poverty reduction in Botswana: A multivariate causality test. Economics and Sociology, 12(3): 54-66. http://doi:10.14254/2071-789X.2019/12-3/4

Nkoro, E., Ikue-John, N., Okeke, W., Amabuike, I. L. \& Ajaba, J. A. (2019). Power supply and the performances of small and medium scale enterprises (SMEs) in Rivers State. International Journal of Business Ecosystem and Strategy, 1(1): 55-62. https://doi.org/10.36096/ijbes.v1i1.95

Nyanzu, F. \& Adarkwah, J. (2016). Effect of power supply on the performance of small and medium-sized enterprises: A comparative analysis between SMEs in Tema and the northern part of Ghana. MPRA Paper No. 74196.

Ogundipe, A., Oduntan, E. A. Adebayo, O. \& Olagunju, K. (2016). Agricultural productivity, poverty reduction and inclusive growth in Africa: Linkages and pathways. Asian Journal of Agricultural Extension, Economics and Sociology, 18(1): 1-15.

Okwanya, I. \& Abah, P. O. (2018). Impact of energy consumption on poverty reduction in Africa. CBN Journal of Applied Statistics, 9(1): 105-139.

Oppong, N. Y. (2017). Still the dark continent? Towards contextual methodological approaches to management development research in foreign multinational firms in Africa. International Journal of Cross-Cultural Management, 17(2): 237-256. https://doi.org/10.1177/1470595817706384

Phillips, A. W. (1958). The relation between unemployment and the rate of change of money wage rates in the United Kingdom, Economica, 25(100): 283-299. https://doi.org/10.1111/j.1468-0335.1958.tb00003.x

Reyes, C.M., Tabuga, A.D., Asis, R.D. \& Datu, M.B.G. (2012). Poverty and agriculture in the Philippines: Trends in income poverty and distribution. Discussion Paper Series No. 2012-09, Philippine Institute for Development Studies (PIDS), April, http://dirp4.pids.gov.ph/ris/dps/pidsdps1209.pdf.

Ribot, J. \& Peluso, N. (2003). A theory of access. Rural Sociology, 68(2): 153-181. http://dx.doi:10.1111/j.15490831.2003.tb00133.x

Rogers, P., De Silva, R. \& Bhatia, R. (2002). Water is an economic good: How to use prices to promote equity, efficiency, and sustainability. Water policy, 4(1): 1-17.

Santos-Vega, M., Bouma, M. J. Kohli, V. \& Pascual, M. (2016). Population density, climate variables and poverty synergistically structure spatial risk in urban malaria in India. PLOS Neglected Tropical Diseases, 10(12): 1-14. http://doi:10.1371/journal.pntd.0005155

Schelzig, K. (2005). Poverty in the Philippines: income, assets, and access. Retrieved from Asian Development Bank, https://www.adb.org/sites/default/files/publication/29763/povertyphilippines.pdf

Sibt-e-Ali, M., Raza, S. M. F. \& Abidin, S. Z. (2018). Population, poverty and economic development nexus: Empirical study of some selected developing countries. Pakistan Journal of Humanities and Social Sciences, 6(4): 458-476.

Simmet, H. R. (2018). "Lighting a dark continent": Imaginaries of the energy transition in Senegal. Energy Research and Social Science, 40, 71-81. https://doi.org/10.1016/j.erss.2017.11.022

Singh, R. J. \& Huang, Y. (2015). Financial deepening, property rights, and poverty: Evidence from Sub-Saharan Africa. Journal of Banking and Financial Economics, 1, 130-151.

Singh, B., Ramasubban, R. Bhatia, R. Briscoe, J. Griffin, C. C. \& Kim, C. (1993). Rural water supply in Kerala, India: How to emerge from a low-level equilibrium trap. Water Resources Research, 29(7): 1931-1942. https://doi.org/10.1029/92WR02996

Sundaram, K. (2017). Some recent trends in population, employment and poverty in India: An analysis. In Perspectives on Economic Development and Policy in India (pp. 129-167). Springer, Singapore. Follow format

Swe, K. T., Rahman, M., Teng, Y., Abe, S. K., Hashizume, M. \& Shibuya, K. (2020). Impact of poverty reduction on access to water and sanitation in low-and lower-middle-income Countries: Country-Specific Bayesian Projections to 2030. The Lancet Global Health, 1-34. http://dx.doi.org/10.2139/ssrn.3526298

Thurlow, J., Dorosh, P., \& Davis, B. (2019). Demographic change, agriculture, and rural poverty. In Sustainable Food and Agriculture (pp. 31-53). https://doi.org/10.1016/B978-0-12-812134-4.00003-0

Tuason, M. (2002). Culture of poverty: Lessons from two case studies of poverty in the Philippines: One became rich, the other one stayed poor. Online Readings in Psychology and Culture, 8(1). http://dx.doi:10.9707/2307-0919.1069

Ulriksen, M.S. (2012), Questioning the pro-poor agenda: Examining the links between social protection and poverty. Development Policy Review, 30, 261-281. https://doi.org/10.1111/j.1467-7679.2012.00576.x

Workneh, M. A., Eshete, Z. S. \& Figari, F. (2019). Gender inequality, governance and poverty in sub-Saharan Africa. Governance and Poverty in sub-Saharan Africa (October 12, 2019). Follow format

Yamane, T. (1967). Statistics: An Introductory Analysis, 2nd Ed., New York: Harper and Row

Zahonogo, P. (2017). Financial development and poverty in developing countries: evidence from sub-Saharan Africa. International Journal of Economics and Finance, 9(1): 211-220. http://doi:10.5539/ijef.v9n1p211 
Appendix-1

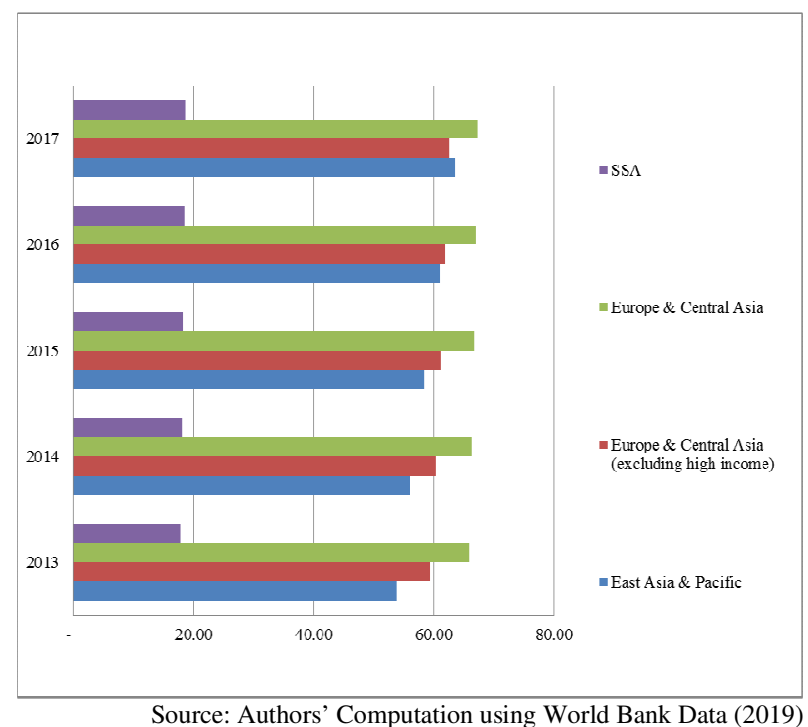

Figure 2. Proportion of Population with Access to Sanitation Across Regions

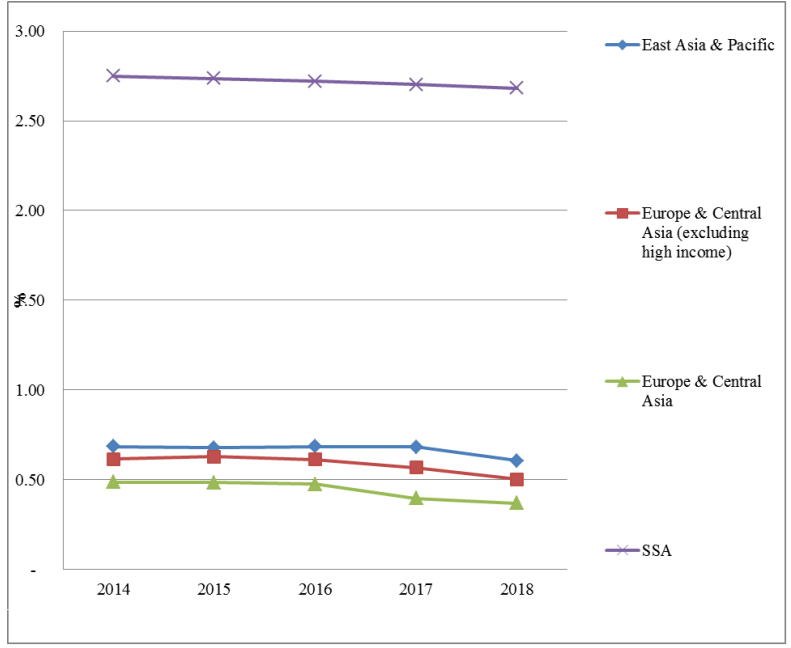

Source: Authors' Computation using World Bank Data (2019)

Figure 3. Population Growth Rate Across Regions 


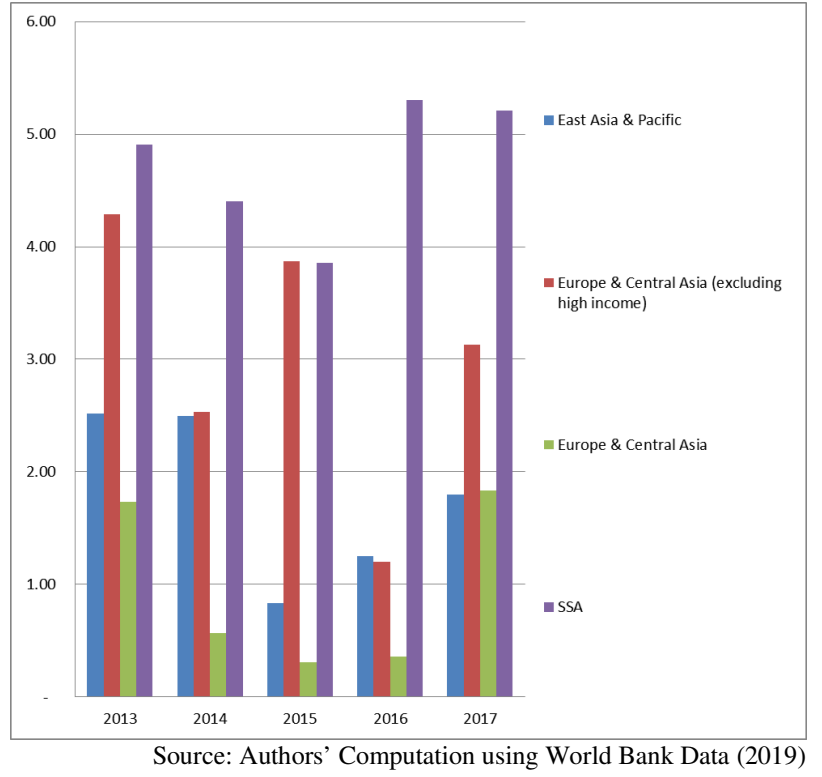

Figure 4. Inflation Rate Across Regions

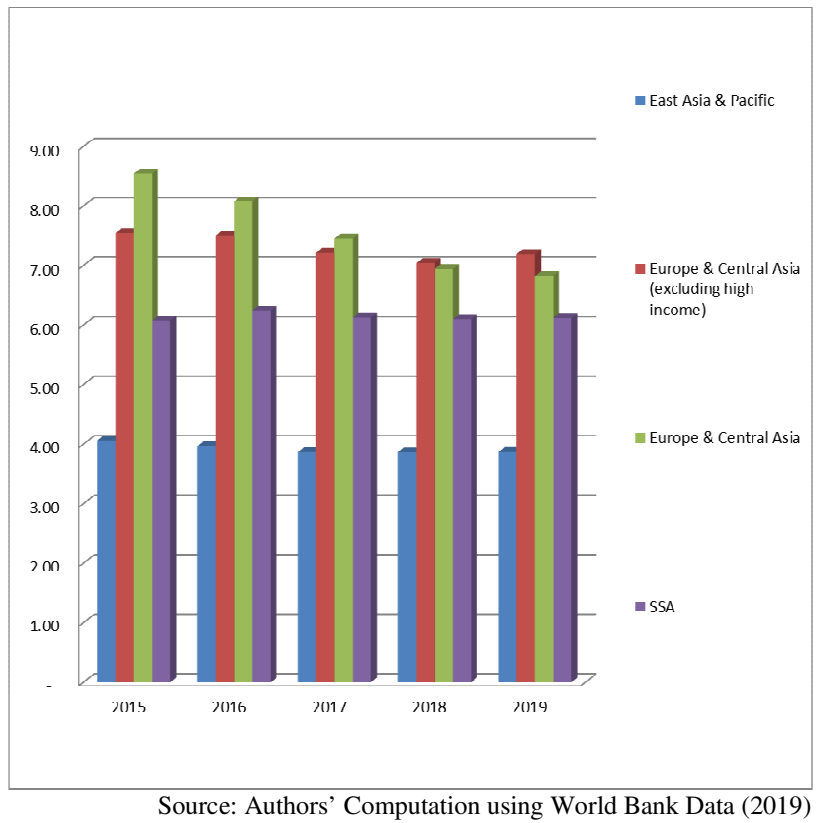

Figure 5. Unemployment Rate Across Regions 


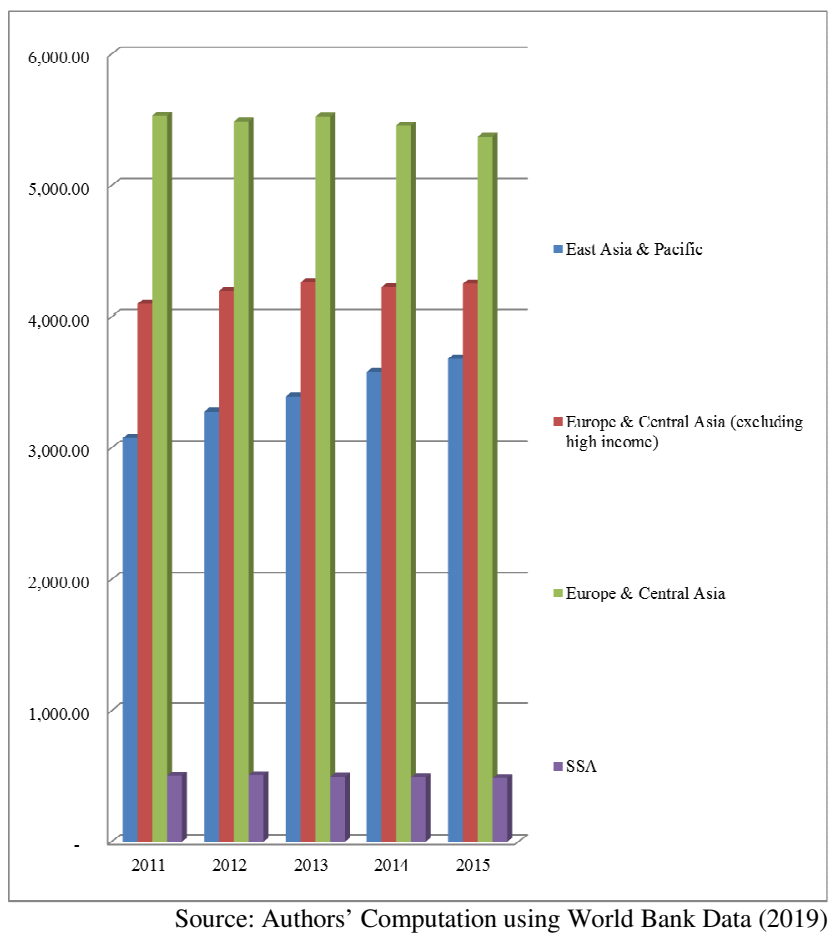

Figure 6. Energy Consumption per Capita Across Regions

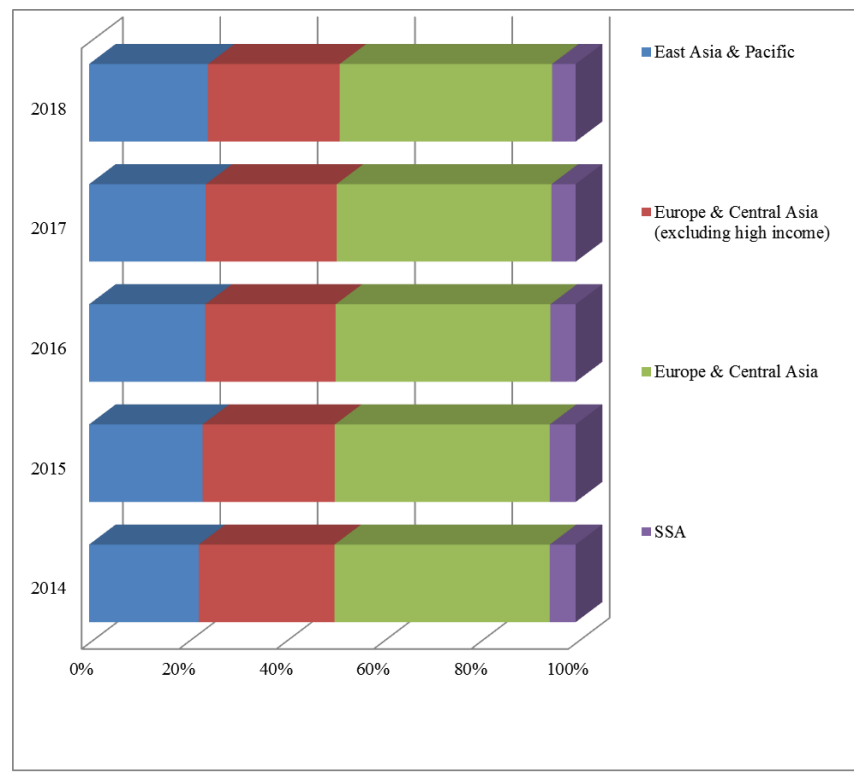

Source: Authors' Computation using World Bank Data (2019)

Figure 7. Proportional Distribution of GNI Across Regions 
Appendix-II

\begin{tabular}{|c|c|c|}
\hline \multirow[t]{2}{*}{ Predictors } & \multicolumn{2}{|c|}{ Poverty (HDI) } \\
\hline & Panel Least Square (PLS) & Robust Least Square (RLS) \\
\hline LogWater (population without & $-0.0134\left(0.0000^{* *}\right)$ & $-0.0133\left(0.0000^{* *}\right)$ \\
\hline \multicolumn{3}{|l|}{ access) } \\
\hline Sanitation (proportion of population & $0.0011\left(0.0000^{* *}\right)$ & $0.0012\left(0.0000^{* * *}\right)$ \\
\hline \multicolumn{3}{|l|}{ with access) } \\
\hline Population growth $(\%)$ & $0.0111\left(0.0000^{* *}\right)$ & $0.0131\left(0.0000^{* *}\right)$ \\
\hline LogGNI_PC & $0.2490\left(0.0000^{* *}\right)$ & $0.2476\left(0.0000^{* *}\right)$ \\
\hline LogEnergy consumption per capita & $0.0203\left(0.0001^{* *}\right)$ & $0.0267\left(0.0000^{* *}\right)$ \\
\hline Inflation rate (consumer price & $-0.0001(0.3428)$ & $-3.42 \mathrm{E}-05(0.7693)$ \\
\hline \multicolumn{3}{|l|}{ index) } \\
\hline Unemployment rate (proportion of & $-0.0006\left(0.0133^{*}\right)$ & $-0.0007\left(0.0114^{*}\right)$ \\
\hline \multicolumn{3}{|l|}{ total labor force) } \\
\hline R-Squared & 0.8782 & 0.6789 \\
\hline$f$-Statistics & $589.0704\left(0.0000^{* *}\right)$ & \\
\hline Durbin-Watson & 2.12546 & \\
\hline
\end{tabular}

Table 3. Estimates of Predictors of Poverty in Sub-Saharan Africa 


\begin{tabular}{lccc}
\hline Null Hypothesis & $f$-statistics & Probability & Remarks \\
\hline Logwater does not Granger cause poverty & 1.9624 & 0.1415 & No causality \\
Poverty does not Granger cause Logwater & 10.6582 & $3 . \mathrm{E}-05$ & Causality \\
Sanitation does not Granger cause poverty & 5.2189 & 0.0057 & Causality \\
Poverty does not Granger cause Sanitation & 2.1427 & 0.1183 & No causality \\
Population growth does not Granger cause poverty & 9.0254 & 0.0001 & Causality \\
Poverty does not Granger cause Population growth & 25.7669 & $2 . \mathrm{E}-11$ & Causality \\
LogGNI_PC does not Granger cause poverty & 12.5463 & $5 . \mathrm{E}-06$ & Causality \\
Poverty does not Granger cause LogGNI_PC & 19.8936 & $5 . \mathrm{E}-09$ & Causality \\
LogEnergy does not Granger cause poverty & 0.0260 & 0.9743 & No causality \\
Poverty does not Granger cause LogEnergy & 2.8873 & 0.0566 & Causality \\
Inflation does not Granger cause poverty & 0.2367 & 0.7893 & No causality \\
Poverty does not Granger cause Inflation & 2.2649 & 0.1048 & No causality \\
Unemployment does not Granger cause poverty & 5.2189 & 0.0057 & Causality \\
Poverty does not Granger cause Unemployment & 0.4355 & 0.7247 & No causality \\
\hline Source: Authors' Computation using World Bank Data & &
\end{tabular}

Table 4. Direction of Causation between Poverty (HDI) and its Predictors in SSA Economies 